\title{
What can self-disorders in schizophrenia tell us about the nature of subjectivity? A psychopathological investigation
}

\author{
Helene Stephensen ${ }^{1} \cdot$ Josef Parnas ${ }^{1,2}$
}

Published online: 15 October 2017

(C) The Author(s) 2017. This article is an open access publication

\begin{abstract}
The purpose of this article is to show how schizophrenia, understood as a distortion of the most intimate structures of subjectivity, illustrates the nature of subjectivity as such, while at the same time how philosophical considerations may help to understand schizophrenia. More precisely, schizophrenic experiences of self-alienation seem to reflect a congealing or concretization of a form of differentiation or potential alterity implicit in the dynamic nature of subjectivity. In other words, we propose that the structure of subjectivity includes potential divisions and fissures that condition the experiences of radical selfalienation seen in schizophrenia. In order to elucidate how this alterity emerges within the self in schizophrenia and in order to consider its conditions of possibility we examine the disorders of the self as described in phenomenological psychopathology. We especially use the work of the Japanese psychiatrists Mari Nagai, her teacher Bin Kimura, and the French psychiatrist Henry Ey, supplemented with clinical material from our own research. Finally, we shed light on the development of the psychotic symptoms such as hallucinations and delusions, which are understood as the expressions of a radical alterization (i.e., becoming other) of the self.
\end{abstract}

Keywords Self $\cdot$ Subjectivity $\cdot$ Schizophrenia $\cdot$ Alterity $\cdot$ Phenomenology

The I-I is a mathematical point that does not exist at all

—Kierkegaard, Concluding Unscientific Postscript

Helene Stephensen

helene.borregaard.stephensen@ regionh.dk

1 Mental Health Centre Glostrup, Copenhagen University Hospital, Brøndbyøstervej 160,

DK-2605 Brøndby, Denmark

2 Center for Subjectivity Research, University of Copenhagen, Karen Blixens Plads 8,

DK-2300 Copenhagen S, Denmark 


\section{Introduction}

Since the beginning of philosophy, madness has played a crucial role as limit case and magnifying glass. ${ }^{1}$ According to Hegel, the contradictory nature of subjectivity (e.g., the contradiction of being an individual and at the same time "identical with the universal natural soul") becomes distorted and amplified in madness, thereby providing an enlightening perspective for the exploration of subjectivity as such (Hegel 1978, 124-5; Berthold-Bond 1994). Jaspers on the other hand makes it clear that in order for us to grasp the insanity we have to operate with some sort of assumption about the nature of subjectivity (Jaspers 1997). We will use schizophrenia as an example of an illness that provides a possibility of this reciprocal elucidation. More precisely, schizophrenic experiences of radical self-alienation seem to reflect a concretization or congealing (understood as solidification) of a form of differentiation or potential alterity implicit in the dynamic nature of subjectivity. This quote from a schizophrenic patient vividly illustrates the form of self-alienation or -fragmentation characteristic of the illness.

When I'm with others, there are two $I s$ : the $I$ who is among them, and the $I$ who objectively looks at this $I$. No matter how much I am absorbed in something, there is always an $I$ that looks on from the outside dispassionately. This latter, outer self is always managing and controlling me. Even when I talk with others, the outer self listens to their words and tell them to the inner self. After listening to this, the inner self starts to talk. The inner self speaks what the outer self commands it to do. (Nagai 1990) ${ }^{2}$

The patient articulates a ceaseless self-monitoring involving a sense of alterity in the midst of her most intimate self-awareness. This seems to involve a certain sense of selfredoubling or self-duplication within self-experience, where the patient's own experiences appear alien and intrusive - importantly not to be confused with having multiple personalities (i.e., dissociative identity disorder).

In the phenomenological tradition, the relation between subjectivity and alterity or self and other has been widely debated (Zahavi 1999). Rather than being a selfenclosed entity, subjectivity is considered to be inherent to the stream of experience directed towards something other than itself. Therefore the question arises to what extent self-awareness is permeated by alterity. In this paper we aim to show how schizophrenia may provide an illuminating perspective for this discussion. There have already been attempts to inform the philosophical discussions on the nature of selfhood, personhood, embodiment and the like, using schizophrenia, and especially one of its flamboyant symptoms, namely the phenomenon of thought insertion (e.g., Frith 1992; Campbell 1999; Gallagher 2004; Lane 2015). However, the more subtle, pervasive and fundamental disorders of self-experience - only recently rediscovered in the mainstream psychiatry (Sass and Parnas 2003; Parnas and Handest 2003; Parnas et al. 2005;

\footnotetext{
${ }^{1}$ See for instance Plato's Phaedrus.

${ }^{2}$ A translation of one of Mari Nagai's texts into English has recently appeared (see Motobayashi et al. 2016). We refer to quotes from this translation as "Nagai (1990)" for the sake of clarity.
} 
Parnas and Henriksen 2014) - have not yet been used systematically in a philosophical context. It should be emphasized, that we do not aim at presenting a new or original account of subjectivity, but rather to argue that the structure of subjectivity includes potential divisions and fissures that condition the experiences of radical self-alienation seen in schizophrenia.

We will begin by introducing the reader to the notion of self-disorders in schizophrenia as described in phenomenological psychopathology, and in order to illustrate how alterity emerges within subjectivity in schizophrenia and in order to consider its conditions of possibility we will especially use the work of the Japanese psychiatrists Mari Nagai, ${ }^{3}$ her teacher Bin Kimura, and the French psychiatrist Henry Ey, supplemented with clinical material from our own studies.

\section{Self-disorders in schizophrenia}

References to a disordered ego or self stretch back to the very foundation of the notion of schizophrenia and its predecessor "dementia praecox" (i.e., Kraepelin and Bleuler). Already in Bleuler's magnum opus on schizophrenia from 1911 it becomes evident that no single or demarcated symptom or sign is specific to schizophrenia, rather a specific Gestalt unifies the diversity of manifestations, a Gestalt of profoundly changed subjectivity (Bleuler 1950; Parnas 2011). It should be remarked, that contemporary psychiatry has lost sight of this Gestalt due to the development and dominance of the psychiatric operational diagnostic systems (i.e., DSM-V and ICD-10), which gradually have left behind the focus on the actual lived world of the patients and abandoned the original rich psychopathological descriptions in favor of simple questionnaires and checklists (Parnas and Bovet 2015).

In contrast to this development, the phenomenological approach to schizophrenia has undergone something of a revival the last couple of decades. Phenomenological informed empirical research of the schizophrenia spectrum disorders (i.e., schizophrenia and schizotypal disorders) has demonstrated its most basic pathology as a global alteration of subjectivity (viz. self-disorders) (Parnas et al. 1998, Møller and Husby 2000; Parnas et al. 2005; Nordgaard et al. 2013; Parnas and Henriksen 2014).

It is important to note, that speaking of disorders of the self in schizophrenia is not identical to speaking of a simple loss or lack of self or self-awareness. Rather, as already indicated, the disorders concern global or structural modifications of subjective life and not deficits of isolated mental states or functions (e.g., sense of ownership or agency). Briefly put, self-disorders imply a disturbance of the dynamic structure of the articulation of the first-person-perspective involving a fragile sense of self-presence and a tendency to hyperreflexivity, which implies active or passive modes of increased and intrusive self-awareness (Sass and Parnas 2003; Parnas and Sass 2011; Parnas and Henriksen 2016). In the following, we will briefly illustrate the most important clinical features of this altered subjective life in schizophrenia.

In the pre-onset stages of schizophrenia, typical complaints from patients gravitate around feelings of not truly existing, not being fully present, or being ephemeral. In

\footnotetext{
${ }^{3}$ We have decided to present Nagai's writings as an example of a very sophisticated analysis of subjectivity and schizophrenia, quite early in the history of contemporary phenomenological psychopathology.
} 
clinical examples taken from Bleuler, a very intelligent patient had to spend hours of strenuous inner work "only for a brief moment to find his own self" while another patient reports that she "is not really herself, she is merely a reflection of herself" and yet others report that they "can't catch up with themselves," that they "have lost their individual self" (Bleuler 1950, 145). These reports all indicate that the patients suffer from an inner alteration almost impossible to verbalize. Patients may also use phrases such as "I am losing contact with myself," "I am turning inhuman," or "I have a strange ghostly feeling as if I was from another planet. I am almost nonexistent" (Parnas and Handest 2003). This fragile sense of self concerns a primary and immediate self-acquaintance, rather than reflective self-recognition or -knowledge, which also becomes manifest when patients report of an experiential distance to their own thoughts, feelings, or actions. A patient articulately expressed this distance between himself and his stream of experience:

I am no longer myself (...) I feel strange, I am no longer in my body, it is someone else (...) I walk like a machine; it seems to me that it is not me who is walking, talking, or writing with this pencil (Parnas and Handest 2003, 126-7)

This profound and immediate self-alienation is interrelated with not feeling present in or attuned with the world or other people, or as Fuchs frames it, self-disorders in schizophrenia concern a disturbance of the "embodied self," which implies disturbances in the automatic immersion and involvement in the world and with others (Fuchs 2015). The world and others may appear unfamiliar, unreal, enigmatic, staged or meaningless, which may be accompanied by a feeling of not being affected by one's surroundings, or as a patient puts it: "I live in a sort of bubble, where the world does not matter. I lack synchrony with the people around me." (Henriksen and Nordgaard 2014, 437).

Closely linked to this lack of attunement with the world and others are difficulties in grasping what is relevant and appropriate in a given situation. Blankenburg famously designated this as a disturbance of "common sense" or as "a loss of natural evidence" (Blankenburg 1971). One of our patients explained that he mostly could not overcome social interaction due to his inability to be "immediate," and he was stunned, that it apparently was so easy for others to be "natural." A related aspect to this estrangement is feelings of being profoundly different from other people (viz. 'Anderssein'). Often this feeling has been present since childhood and it is frequently difficult to formulate except in vague terms of just being "wrong" or "different" (Parnas and Henriksen 2014), which is illustrated in the following vignette:

I'm somehow in all respects different from others. My facial features, the feeling I express, the environment I was born in ... anyway, it's all different. I have to do everything anew from the beginning. (Nagai 1990)

It is important to remark that even though patients appoint particular areas in which they feel different, as in the case above (e.g., facial features), this seems to be a way of making sense of a more primary and pervasive sense of being different. 
Now, these disturbances in feeling self-present and feeling anchored in the world and among others are linked to the tendency to excessive reflection or exaggerated selfawareness. We will now proceed to explore how this excessive self-awareness, characteristic for schizophrenia, involves a specific alterity emerging within the self.

\section{Nagai: Self-duplication and internal alterity in schizophrenia}

Nagai highlights a certain form of "excess of introspection" as a prominent feature of schizophrenia (Nagai 1991). According to Nagai, the tradition of phenomenological psychopathology has neglected paying sufficient attention to the phenomenon of (excessive) introspection in schizophrenia. This neglect must in part be seen as the result of the view held by for example Blankenburg, who regarded reflectivity as a compensatory mechanism for deficient pre-reflective attunement to the world (lack of common sense or natural evidence) (Blankenburg 1971). In this understanding, the increased reflectivity is not abnormal in itself but rather a secondary act or response to primary pathological changes. Furthermore, Nagai regards the neglect as the result of a common view among psychiatrists, namely, that introspection is a good thing in itself equating it to insight into one's mental condition or in psychiatric terminology "insight into illness". ${ }^{4}$ On the contrary, Nagai suggests that reflection or introspection in itself can be part of the problem. ${ }^{5}$

To understand this phenomenon, it is crucial that Nagai distinguishes between two types of introspection, namely "simultaneous introspection" and "post facto introspection" (Nagai 1990). In short, post facto introspection designates what we would normally call "reflection" or "self-reflection," and it is this type of introspection that she regards as compensatory. According to Nagai, the ordinary sort of introspection always occurs "post facto," meaning that it is a "retrospective gaze that is turned on the past self" (Nagai 1991). An example of this is when a person has erred and afterwards reflects on what he or she did wrong. It is not uncommon to find an increase of this type of introspection among schizophrenic patients. In clinical terms, patients may scrutinize what happened during the day to grasp what the meaning was, or anticipate future events or situations in analytic detail due to the insecure sense of self and due to problems with common sense.

When Nagai speaks of "post facto" introspection, it at first glance appears to designate attending to a past experience as opposed to attending to an ongoing experience. More precisely, however, it implies that in reflection one always grasps oneself in a delayed manner. In Husserlian terms self-reflection is always grasping the retentional moments of the stream of consciousness (Husserl 1973). Differently put, the reflecting moment is always elusive since it cannot grasp itself. Ryle articulates this elusiveness with the analogy of someone trying to jump up to the head of their own shadow, being always just one step behind (Ryle 1949). This implies a differentiation between a "reflecting" and "reflected" moment, that is, between the moment that is the

\footnotetext{
${ }^{4}$ On the contrary, it is not uncommon in schizophrenia that high levels of introspection and reflexivity coexist with "poor insight" into illness although this is further complicated by the phenomenon of "double bookkeeping" (Henriksen and Parnas 2014).

${ }^{5}$ Similarly, Sass and Parnas (2003) consider hyperreflexivity as being equiprimordial to diminished selfaffection.
} 
object of the introspection, and the moment that performs the introspection akin to Husserl's notions of "objective subjectivity" and "functioning (operative) subjectivity" (Husserl 1973, 431). In ordinary self-reflection, these moments are merely implied or potential, but hidden in the unity of experience.

According to Nagai, there is an "established relationship" between the two moments in reflection and it is precisely this established relationship that becomes insecure in "simultaneous introspection," which we will now turn to.

Simultaneous introspection signifies a ceaseless and involuntary self-observation or selfmonitoring that occurs even when one is occupied with worldly matters. As Nagai puts it "even in simple, everyday experiences wherein ordinarily, one would 'forget oneself,' our patients never quite forget themselves" (Nagai 1991). With the notion of "simultaneous introspection," Nagai tried to capture a specific form of excessive reflection being itself problematic, in making it very difficult for the patient to become fully engaged or immersed. We have already quoted one of Nagai's patients who suffered from this ceaseless selfobservation, and it is also vividly illustrated in the following quote from another patient:

I'm too self-conscious. I'm constantly watching, staring at myself. Because I'm staring at myself so intensely, when I watch TV, it doesn't get inside my head. Even while talking with someone, all I do is watch myself. So I can't really get what the other person is talking about... I don't feel at ease when I'm in a place where there are many people. I constantly feel that I'm being watched. (Nagai 1991)

It is important to emphasize that not all schizophrenia patients have that degree of introspective access to or awareness of "the inner workings" of the pathological changes they experience, and may therefore be unable to verbalize these disturbing experiences as clearly as in the vignettes presented in this paper. Nonetheless, these vignettes seem to point to essential features of the illness. The difficulty in articulating these experiences may also stem from the fact that it is much easier to express the content of an introspection than the fact that one is introspecting.

As opposed to post facto introspection, where the reflecting moment is elusive, simultaneous introspection seems to be this very impossible movement where the reflecting moment, as Nagai puts it, is trying to grasp itself as it "appears at this very moment" (Nagai 1991). This simultaneity however, is by no means tantamount to a convergence of the reflecting and reflected moment. Instead of experiencing an unproblematic self-coincidence the vignettes above manifest experiences of a gap or distance and a sense of self-fragmentation.

The self-alienation in question concerns a characteristic self-fragmentation or selfredoubling, with Nagai's words, involving a "formation of two quasi-subjects" (ibid.). The "formation of two quasi-subjects" signifies the experience of being at the same time someone who is engaged in actual situations, and someone who is, so to speak, watching the scene from behind. Most importantly, there is an experience of noncoincidence between the two quasi-subjects. It is important to note that the reason we call them "quasi" is that none of them can be considered as autonomous, true subjects.

In the second vignette, the alienation involved in the experience of self-redoubling is perhaps even more conspicuous, because the constant self-observation has developed into a feeling of actually being watched by others, and not merely by oneself. Here, the 
aspects of the patient's self have become externalized, and he grasps himself as an 'other' in a concrete manner. This experience is exactly what the notion of "alterization" refers to, which we will return to in the below.

It should be remarked, that it is of course not completely unordinary to observe oneself while at the same time interacting with the world. Especially in disquieting situations (exams, networking events etc.) one may become painfully self-conscious hindering one's natural performance or engagement. In such cases of self-observation we witness a disturbing self-reflection, which nonetheless follows the structure of normal reflection where the reflecting ego remains phenomenally elusive. It is therefore not the simultaneousness of a self-observation alone that makes it characteristic for schizophrenia, and therefore we suggest to replace the notion of "simultaneous introspection" with "involuntary selfwitnessing." The term "introspection" is replaced because the term "self-witnessing" captures the involuntary and passive character of the experience.

To elucidate the experience of involuntary self-witnessing, it is helpful, as Nagai proposes, to introduce an externalized visual analogy: namely, that of looking at oneself in the mirror. Following this analogy, on the one hand, one is "looking at oneself in the mirror", and on the other hand, one is "being looked at by oneself in the mirror" (Nagai 1991). We can add that most people can relate to having alienating experiences when looking at themselves in the mirror, but the sense of alienation remains extremely transient. In schizophrenia this experience of "looking at oneself in the mirror" is alienating in a much more radical manner. When we look in the mirror, the two moments of "looking at" and "being looked at" might present themselves as two distinct moments, but crucially they remain parts of one and the same experience. In schizophrenia, however, these two moments come to the fore as separate and the very link between them has become insecure. ${ }^{6}$ This sometimes even evolves into a sense of not knowing on which side of the mirror one is located metaphorically speaking.

Returning to experiences of self-redoubling in schizophrenia, we propose that the formation of two quasi-subjects may be a reification of a more basic level of differentiation implicit and potential in all subjectivity. One of our patients gave a very articulate account that suggests such a process:

I think it's strange that you can experience something that you then at the same time register, as if you have.. as if there is a difference between the one who experiences something, and the one who experiences that one experiences something... I feel like that about my own thoughts... It is as if there is a true inner me who knows what I think, feel, and ought to do, but is hidden. Who I am and act according to is the 'outside person' who interacts with others and... It's difficult to explain. I'm sometimes in contact with the true me, actually every day, but it is only because of distrust in the 'outside person'... There is a tension between the two... I don't feel I'm any of them. Actually, I am afraid that if the 'outside person' were peeled off, then there would be nothing.

\footnotetext{
${ }^{6}$ Statements like "there is always an I that looks on" or "I am constantly watching myself" at first glance seem to imply a relational structure, but in fact there is no stability in the structure making it short from being a true relation. In Nagai's understanding, we still find the two moments of "watching" and "being watched," but instead of forming a stabile structure the two simultaneous moments alternately seem to occupy the places of watching and being watched.
} 
Just as in the two previous vignettes, the patient expresses a continuous observation of his self involving self-fragmentation. What is important to note here, is the fact that he furthermore articulates some sort of gap or distance implicit within experience itself, that is, the separation allowing for a distinction between the experience of something itself, and the experience that you experience something. As Grøn puts it with a reference to Hegel, consciousness does not relate to itself as an object, but rather it "experience itself in experiencing the world." (Grøn 2010, 84; our italics). Ultimately, it is a congealing of this differentiation that leads to a sense of duplication or redoubling of the self in schizophrenia.

In schizophrenia, this normal but only potentially present gap between the two moments of reflection becomes reified and appears in the patients' awareness as a sense of self-duplication. We find an indication of such a dynamism, when the patient explains that his "inner self" is not "available to him," and that he is only in touch with the "true inner me" when it suddenly interrupts the "outside person" saying:" you don't really think that" and the like. The reflection has so to speak come to the fore as only a reflection, and not merely as a constitutive part of the lived experience. This does indeed seem to clarify the signification of him explaining that it is only because of "distrust" in the outside person that he is in contact with the "true me." It is for this very reason that he did not like to speak to psychiatrists and psychologists, because he had no idea if what he was telling them about himself was true. He said that everything he felt and thought was "unreliable."

\section{Concretization of the potential differentiation}

In sum, we witness in those cases a disturbing change in the stream of consciousness. A normally tacit or implicit sense of self has become replaced by a constellation where partly objectified quasi-subjects emerge at the border of the pre-reflective and thematic consciousness.

Following Husserl and Sartre, Nagai endorses the notion of "pre-reflective selfawareness," i.e., a tacit self-awareness that one normally is not thematically conscious of. Pre-reflective self-awareness is given as the self-manifestation of the stream of consciousness and as such no self appears explicitly. According to Nagai this prereflective self-awareness becomes prominent in an obtrusive manner in schizophrenia. She therefore tentatively proposes that simultaneous self-witnessing is a sort of awareness of the pre-reflective (Nagai 1991).

Perhaps the notion "awareness" is misleading, since it should not refer to a cognitive or thematic attention (see also Fuchs 2015; Stanghellini et al. 2014). On the contrary, patients often find it very difficult to articulate their experiences. When a normally implicit pre-reflective structure becomes available to experience it would seem to imply reflection, which is not the case in schizophrenia. Rather it is a sort of concretization of the pre-reflective structure making it emerge in consciousness. As such, the presence of those quasi-subjects in the stream of experience points to a certain objectification of subjectivity.

With a reference to Descartes' Cogito Nagai argues that a quasi-relation must already be established before its development into reflective self-relation (Nagai 1991, ch. 9). Descartes famously wrote in the second part of the Meditations: 
I am now seeing light, hearing a noise, feeling heat. But I am asleep, so all this is false. Yet, it certainly seems to me that I see, hear and am warmed. This cannot be false. (Descartes 1984)

It may be helpful here to refer to Michel Henry's reading of the Cogito. In Descartes' quest to secure certain knowledge, the Cogito is identified as the securing foundation, but according to Henry this basic level of phenomenality is an example of auto-affection, i.e., the subjectivity's intrinsic affectivity (Henry 1963; 1985). For example, in the case of perception, the awareness of perceiving arises through self-affection of the intentional act of perception. In Husserlian terminology we might speak of "double sensation", referring to a hand touching itself alternating between touching and being touched (Husserl 1973; Zahavi 1998).

Henry is keen to insist on the non-relational nature of self-affection, precluding any division or chiasm, although he often talks of dynamism and the vital rhythm of subjectivity (Henry 1975). In our view, the notion of pre-reflective self-awareness is indispensable for understanding subjectivity. However, we consider self-affection as an outcome of incessant differentiation and coalescing of affective moments (see also Rogozinski 2010). In the process of differentiation some of these moments acquire the potential to form an alterity. The structure of the self shows itself in dynamics of bifurcations and fusions of affective moments. This pre-reflective circular movement enables self-reflection by offering a fissure, which normally becomes rapidly sealed and submerged assuring the sense of self-coincidence. In schizophrenia, this fissure becomes congealed, allowing for alterization and a formation of obtrusive quasi-subjects. As Nagai argues, as long as there is a balance between "seeing" and "being seen," (implicit in auto-affection) it is not necessary for this structure to become experiential prominent (Nagai 1991).

\section{Alterization and haunting otherness}

In order to clarify what it means that the fissure or differentiation implicit in the dynamic structure of subjectivity becomes reified or concretized in schizophrenia we will now turn to Ey and Kimura.

With the notion of "alterization," Ey describes the development of the psychotic symptoms such as hallucinations and delusions as an articulation of the differentiation implicit in subjectivity (Ey 1973). Alterization signifies a process where subjectivity undergoes an alteration, involving a pronunciation of a sense of alterity in the midst of the patients' most intimate self-experience (Ey 1973, 418). In other words, aspects of the self are increasingly articulated as being alien or "other," and this otherness in the midst of the self becomes haunting. In this process we find an increasing experience of redoubling within self-experience itself as one's own thinking appears in its otherwise merely implicit alterity.

What I think becomes an object that detaches itself from me. What $I$ say to myself becomes what someone says to me. I talk to myself becomes it talks in me. Generally speaking, my thinking is experienced as that of another (Ey 1973, 420; our translation and italics) 
It is imaginable how an increase in these experiences of oneself as being Other may ultimately lead to auditory hallucinations such as voices commenting on the patient's on-going behaviour or voices that discuss the patient in the third-person - as is noted, two characteristic symptoms of schizophrenia (Parnas and Urfer-Parnas 2017). It is likewise understandable how these experiences may develop into the emblematic schizophrenic delusions of being persecuted, monitored or influenced by a machine or otherworldly creature, or the like.

When my thinking is experienced as that of another, I become a subject to this Other. As Ey points out, this Other appears as intruding the most intimate, secret and private essence of being "me" (ibid.). The character of this otherness must be distinguished from the ordinary mode of the appearance of the "real other." As Naudin and Azorin (1997) point to, the intruding, hallucinatory or influencing Other in schizophrenic selfawareness, lacks the traits of the "real other" because it is never given perspectivally and appears ever-present while at the same time always furtive and foreign. The subject therefore has no way of protecting itself from this intrusive Other, often presented as some kind of haunting element within self-consciousness.

It is in this sense we suggest that the increasing feeling of alterity in schizophrenia could be understood as a congealing of a basic level of differentiation implicit in the structure of subjectivity. Differently put, it is exactly the differentiated nature of subjectivity that renders it vulnerable.

In the same vein, Kimura questions the mere possibility of understanding "intrapsychic splitting" (i.e., internal alterity) in schizophrenia if one considers subjectivity to be a monolithic, uninterrupted, homogenous interiority (Kimura 2001). Rather, according to Kimura, subjectivity is fundamentally relational in the respect that it is constituted by a double "in-between" ("aïda"), that is, between one and the other self and between the self and the world (Kimura 1992). Crucially, the notion of "inbetween" is not to be understood as a static or spatial distance between two different things, but rather as a dynamic and generative movement that differentiates one thing from the other. Kimura quotes here the famous motto from Kierkegaard claiming that subjectivity ultimately is nothing other than 'a relation that relates itself to itself' (ibid.). Kimura argues that only such an understanding of the self renders schizophrenic experiences possible, because it is this constitutive alterity that remains exposed or non-integrated in schizophrenia. Put differently, it seems to be the dynamic nature of the "in-betweens" that is disturbed in schizophrenia, in that, the otherness of subjectivity has become concretized or thickened. Kimura captures it in the following way:

The significant change of 'being oneself' in schizophrenia is found in questioning the internal difference that constitutes it [i.e., being-oneself], where one of the moments, alterity, is not integrated into the identity of the self, but as such remain naked (ibid. 127; our translation and addition in square brackets)

In other words, the precondition for being able to recognize oneself, on an implicit or immediate level, consists in the interplay of integration and differentiation. Alterity is thus a constitutive feature of subjectivity, and in schizophrenia this alterity remains exposed or non-integrated, and one becomes Other to oneself in a concrete manner. This otherness is therefore a precondition for the self-duplication occurring in 
schizophrenia. In this manner, schizophrenia is as Kimura puts it "all too human," because it amplifies a fundamental feature of the structure of subjectivity.

In sum, both Kimura and Ey make it evident that it is exactly the differentiated nature of subjectivity that renders it vulnerable to the experiences involved in schizophrenia.

\section{Subjectivity and vulnerability}

Whereas in an ordinary engagement with the world the sense of self is experienced only tacitly and pre-reflectively, in schizophrenia this tacit sense of self may become reified into a double structure of quasi-subjects, which intrude on the thematic level and lead to a condition of pronounced self-witnessing. There is therefore a certain duplication of the self, that is, none of the component quasi-subjects plays a role as an independent subject. Rather these quasi-subjects are moments of the duplicated structure of the self. In other words, there is a sort of incomplete split of the self (which in certain cases may progress to a clearly delusional condition). As Nagai mentions, this peculiar structure of consciousness seems to exemplify the normally unthinkable situation of being aware of the constituting moments of subjectivity. We believe that the pronounced selfduplication or self-redoubling in schizophrenic self-experience is a consequence of a vulnerability in the functioning auto-affection, which normally assures the feeling of self-coincidence in the constant differentiation and reintegration of the subject.

It is debatable whether the self-witnessing, i.e., a constant exchange between the two quasi-subjects, is primary or may be considered from a phenomenological point of view (Minkowski 1927) as a form of "phenomenological compensation," preventing a total disintegration of the ego. In either case, we argue that self-witnessing in schizophrenia arise in the nexus of a complex interplay between the self-organizing structures of subjectivity in its relation to others and the world. This is supported by the fact that many patients describe a clear exacerbation of self-witnessing during interpersonal situations.

Briefly put, we propose, that the radical self-alienation involved in schizophrenia is conditioned by a differentiation in the very constitution of subjectivity. The potentiality for alterization and formation of obtrusive quasi-subjects must be found in some sort of dynamic structure of the self where a process of constant circulation between self and not-self or other, or self and parts of self, takes place.

We will finally take a brief look at Levinas, who provides us with an important clue, when he describes the primordial openness of subjectivity as vulnerability. Levinas conceives of subjectivity in terms of alterity, openness, and exteriority (e.g., Levinas 1987; 2008), which imply that it is in relation to the world and others that one is given to oneself, meaning that we find ourselves as being always already affected by something other than ourselves. The self-acquaintance that precedes any explicit or thematic self-consciousness is not an observation of a "self point" or "I-I point" but, to speak in Heideggerian terms, an acquaintance with oneself as "open" and always already "not yet" oneself (Heidegger 1973, 288). Along the same lines Levinas writes:

The I is not a being that always remains the same, but is the being whose existing consists in identifying itself, in recovering its identity throughout all that happens to it. (Levinas 1979, 36) 
Levinas argues that the primordial openness of subjectivity renders it fundamentally vulnerable (Levinas 1991, 112), and that the sensibility of subjectivity is "exposedness to the other," (Levinas 1991, 75, 122; 1987, 146). The primordial vulnerability of subjectivity is in other words an exposure to the other.

Returning to schizophrenia, it might be understood as a particularly vulnerable form of existence, where the very attempt to protect oneself against this exposedness develops into its very opposite. In other words, a search for an irrelated and nonexposed self is doomed to fail as the search itself further removes its searched-for object, and it becomes a vicious circle. Like in the case of our patient experiencing to have an "inner self" and "an outside person," who intensively searched for an "inner self" not affected by its relations to anything else, and at the same time feared that this search would reveal him to be nothing.

Binswanger (1958) touched upon this phenomenon in his case study of "Ellen West," where he defined the fundamental disturbance to be located in the dynamic and co-constituting relationship between self and world (see Stephensen and Henriksen 2017). According to Binswanger, Ellen West suffered from an irresolvable "breach" between herself and her private world ('Eigenwelt') on the one hand and the world and others ('Mit- und Umwelt') on the other hand (Binswanger 1958, 270). Inspired by Heidegger, Binswanger understood human existence as being the very relation to the world and others (viz. Being-in-the-world), or differently put as being fundamentally co-constituted by the relationships to the world and other persons. A disruption of these the basic constitutive processes, therefore leaves one to feel like an empty subject facing an empty world, as in the case of Ellen West.

Altogether, schizophrenia presents us with a range of experiences that tell us something about the structure of subjectivity as a certain form of "distorted truth" or amplified mirror image. Subjectivity is not just a self-coinciding or irrelational kernel but rather permeated by differentiation and a potentiality for alterity making subjectivity exposed and vulnerable. ${ }^{7}$

\section{Compliance with ethical standards}

Conflict of interest The authors declare that they have no conflict of interest.

Open Access This article is distributed under the terms of the Creative Commons Attribution 4.0 International License (http://creativecommons.org/licenses/by/4.0/), which permits unrestricted use, distribution, and reproduction in any medium, provided you give appropriate credit to the original author(s) and the source, provide a link to the Creative Commons license, and indicate if changes were made.

\section{References}

Berthold-Bond, D. (1994). Hegel on Madness and Tragedy. History of Philosophy Quarterly, 11(1), 71-99. Binswanger, L. (1958). The Case of Ellen West (transl. W.M. Mendel, J. Lyons). In R. May, E. Angel, \& H.F. Ellenberger (Eds.), Existence. A New Dimension in Psychiatry and Psychology (pp. 237-364). New York: Basic Books.

\footnotetext{
$\overline{7}$ The two anonymous reviewers are thanked for their helpful suggestions.
} 
Blankenburg, W. (1971). Der Verlust der natürlichen Selbstverständlichkeit. Ein Beitrag zur Psychopathologie symptomarmer Schizophrenien. Stuttgart: Enke.

Bleuler, E. (1950). Dementia praecox or the group of schizophrenias (transl. J. Zinkin \& N. D. C. Lewis). New York: International University Press.

Campbell, J. (1999). Schizophrenia, the space of reasons, and thinking as a motor process. The Monist, 82(4), $609-625$.

Descartes, R. (1984). The Philosophical Writings of Descartes: Volume II (transl. J. Cottingham, R. Stoothoff \& D. Murdoch). Cambridge: Cambridge University Press.

Ey, H. (1973). Traité des hallucinations, Tome I-II. Paris: Masson.

Frith, C. D. (1992). The Cognitive Neuropsychology of Schizophrenia. Hillsdale: Erlbaum.

Fuchs, T. (2015). Pathologies of Intersubjectivity in Autism and Schizophrenia. Journal of Consciousness Studies, 22(1-2), 191-214.

Gallagher, S. (2004). Neurocognitive Models of Schizophrenia: A Neurophenomenological Critique. Psychopathology, 37(1), 8-19.

Grøn, A. (2010). Self-Givenness and Self-Understanding: Kierkegaard and the Question of Phenomenology. In J. Hanson (Ed.), Kierkegaard as Phenomenologist: An Experiment (pp. 79-97). Evanston: Northwestern University Press.

Hegel, G.W.F. (1978). Philosophy of Mind, vol. 3 of the Encyclopaedia of the Philosophical Sciences (1830) (transl. W. Wallace). Oxford: Clarendon Press.

Heidegger, M. (1973). Being and time (transl. J. Macquarrie \& E. Robinson). Oxford: Blackwell.

Henriksen, M. G., \& Nordgaard, J. (2014). Schizophrenia as a disorder of the self. Journal of Psychopathology, 20, 435-441.

Henriksen, M. G., \& Parnas, J. (2014). Self-disorders and schizophrenia: a phenomenological reappraisal of poor insight and noncompliance. Schizophrenia Bulletin, 40(3), 542-547.

Henry, M. (1963). L'essence de la manifestation. Paris: PUF.

Henry, M. (1975). Philosophy and Phenomenology of the Body (transl. G. Etzkorn). The Hauge: Martinus Nijhof.

Henry, M. (1985). Généalogie de la psychanalyse. Le commencement perdu. Paris: PUF.

Husserl, E. (1973). Zur Phänomenologie der Intersubjektivität II. Texte aus dem Nachlass. Zweiter Teil. In I. Kern (Ed.), Husserliana 14 (pp. 1921-1928). Den Haag: Martinus Nijhoff.

Jaspers, K. (1997). General Psychopathology. Volume One. (transl. J. Hoenig \& M.W. Hamilton). Baltimore/ London: John Hopkins University Press.

Kimura, B. (1992). Écrits de psychopathologie phénomenologique. Paris: PUF.

Kimura, B. (2001). Cogito and I: a bio-logical approach. Philosophy, Psychiatry and Psychology, 8(4), 331336.

Lane, T. (2015). Self, Belonging, and Conscious Experience: A critique of subjectivity theories of consciousness. In R. J. Gennaro (Ed.), Disturbed Consciousness: New Essays on Psychopathology and Theories of Consciousness (pp. 103-139). Cambridge: MIT Press.

Levinas, E. (1979). Totality and Infinity. An Essay on Exteriority (transl. A. Lingis). Den Haag/Boston/ London: Martinus Nijhoff Publishers.

Levinas, E. (1987). Collected philosophical papers (transl. A. Lingis). Dordrecht: Nijhoff.

Levinas, E. (1991). Otherwise than being (transl. A. Lingis). Den Haag: Nijhoff.

Levinas, E. (2008). Outside the subject (transl. M.B. Smith). London: Continuum.

Minkowski, E. (1927). La schizophrénie. Psychopathologie des schizoïdes et des schizophrènes. Paris: Payot.

Møller, P., \& Husby, R. (2000). The initial prodrome in schizophrenia: searching for naturalistic core dimensions of experience and behavior. Schizophrenia Bulletin, 26(1), 217-232.

Motobayashi, Y., Parnas, J., Motobayashi, Y., Kimura, B., \& Toda, D. L. (2016). "The "schizophrenic" in the self-consciousness of schizophrenic patients', by Mari Nagai (1990). History of Psychiatry, 27(4), 493503.

Nagai, M. (1990). Bunretsubyōsha no jikoishiki niokeru 'bunretsubyōsei' [The 'schizophrenic' in the selfconsciousness of schizophrenic patients]. In B. Kimura et al. (Eds.), Seishinbunretsubyō: Kiso to rinshō [Schizophrenia: Its Basic and Clinical Aspects] (pp. 361-368). Tokyo: Asakura Shoten.

Nagai, M. (1991). Naisei no kôzô: Seishin byôrigakuteki kôsatsu (The Structure of Introspection: A Psychopathological Consideration). B. Kimura (Ed.). Tokyo: Iwanami Shoten.

Naudin, J., \& Azorin, J.-M. (1997). The hallucinatory ephoché. Journal of Phenomenological Psychology, 28(2), 171-195.

Nordgaard, J., Sass, L. A., \& Parnas, J. (2013). The psychiatric interview: validity, structure, and subjectivity. European Archives of Psychiatry and Clinical Neuroscience, 263, 353-364. 
Parnas, J. (2011). Disappearing heritage: the clinical core of schizophrenia. Schizophrenia Bulletin, 37(6), 1121-1130.

Parnas, J., \& Bovet, P. (2015). Psychiatry made easy: operation(al)ism and some of its consequences. In K. Kendler \& J. Parnas (Eds.), Philosophical Issues in Psychiatry III: The Nature and Sources of historical change (pp. 190-212). Oxford: Oxford University Press.

Parnas, J., \& Handest, P. (2003). Phenomenology of anomalous experiences in early schizophrenia. Comprehensive Psychiatry, 44(2), 121-134.

Parnas, J., \& Henriksen, M. G. (2014). Disordered Self in the Schizophrenia Spectrum: A Clinical and Research Perspective. Harvard Review of Psychiatry, 22(5), 251-265.

Parnas, J., \& Henriksen, M.G. (2016). Mysticism and schizophrenia: A phenomenological exploration of the structure of consciousness in the schizophrenia spectrum disorders. Consciousness and Cognition, 43, 75-88.

Parnas, J., \& Sass, L. (2011). The Structure of Self-consciousness in Schizophrenia. In S. Gallagher (Ed.), The Oxford Handbook of the Self (pp. 521-546). Oxford: Oxford University Press.

Parnas, J., \& Urfer-Parnas, A. (2017). The ontology and epistemology of symptoms: The case of auditory verbal hallucinations in schizophrenia. In K. S. Kendler \& J. Parnas (Eds.), Philosophical Issues in Psychiatry IV: Classification of Psychiatric Illness (pp. 201-216). Oxford: Oxford University Press.

Parnas, J., Jansson, L., Sass, L. A., \& Handest, P. (1998). Self-experience in the prodromal phases of schizophrenia: A pilot study of first admissions. Neurology, Psychiatry, and Brain Research, 6, 107-116.

Parnas, J., Møller, P., Kircher, T., Thalbitzer, J., Jansson, L., Handest, P., \& Zahavi, D. (2005). EASE: examination of anomalous self-experiences. Psychopathology, 38(5), 236-258.

Rogozinski, J. (2010). The Ego and the Flesh. An Introduction to Egoanalysis (transl. R. Vallier). Stanford: Stanford University Press.

Ryle, G. (1949). The Concept of Mind. Chicago: University of Chicago Press.

Sass, L., \& Parnas, J. (2003). Schizophrenia, Consciousness, and the Self. Schizophrenia Bulletin, 29(3), 427444.

Stanghellini, G., Ballerini, M., Blasi, S., Mancini, M., Presenza, S., Raballo, A., \& Cutting, J. (2014). The bodily self: A qualitative study of abnormal bodily phenomena in persons with schizophrenia. Comprehensive Psychiatry, 55, 1703-1711.

Stephensen, H., \& Henriksen, M. G. (2017). Not Being Oneself: A Critical Perspective on 'Inauthenticity' in Schizophrenia. Journal of Phenomenological Psychology, 48, 124-143.

Zahavi, D. (1998). The Fracture in Self-Awareness. In D. Zahavi (Ed.), Self-Awareness, Temporality, and Alterity. Central Topics in Phenomenology (pp. 21-40). Dordrecht/Boston/London: Kluwer Academic Publishers.

Zahavi, D. (1999). Self-awareness and Alterity. A Phenomenological Investigation. Evanston: Northwestern University Press. 